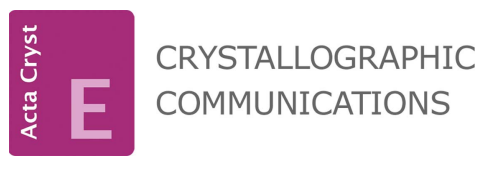

ISSN 2056-9890

Received 7 May 2021

Accepted 1 June 2021

Edited by D. Chopra, Indian Institute of Science Education and Research Bhopal, India

Keywords: polyiodides; formamidinium; formamidinium triiodide; reactive polyiodide melts; Raman spectroscopy; DFT; crystal structure.

CCDC reference: 2087353

Supporting information: this article has supporting information at journals.iucr.org/e

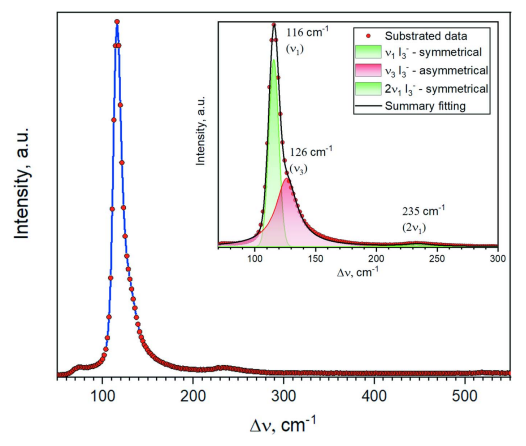

\section{Crystal structure of new formamidinium triiodide jointly refined by single-crystal XRD, Raman scattering spectroscopy and DFT assessment of hydrogen-bond network features}

\author{
Artem A. Ordinartsev, ${ }^{a}$ Andrey A. Petrov, ${ }^{a}$ Konstantin A. Lyssenko, ${ }^{b}$ Andrey V. \\ Petrov, ${ }^{c}$ Eugene A. Goodilin ${ }^{\mathrm{a}, \mathrm{b}, \mathrm{d}}$ and Alexey B. Tarasov ${ }^{\mathrm{a}, \mathrm{b}}$ *
}

\begin{abstract}
aLaboratory of New Materials for Solar Energetics, Faculty of Materials Science, Lomonosov Moscow State University, 119991 Moscow, Russian Federation, bDepartment of Chemistry, Lomonosov Moscow State University, 119991 Moscow, Russian Federation, 'Institute of Chemistry, Saint-Petersburg State University, 198504, Saint-Petersburg, Russian Federation, and ${ }^{\mathbf{d}}$ Institute of General and Inorganic Chemistry, 119991, Moscow, Russian Federation. *Correspondence e-mail: alexey.bor.tarasov@yandex.ru
\end{abstract}

A novel triiodide phase of the formamidinium cation, $\mathrm{CH}_{5} \mathrm{~N}_{2}{ }^{+} \cdot \mathrm{I}_{3}{ }^{-}$, crystallizes in the triclinic space group $P \overline{1}$ at a temperature of $110 \mathrm{~K}$. The structure consists of two independent isolated triiodide ions located on inversion centers. The centrosymmetric character of $\mathrm{I}_{3}{ }^{-}$was additionally confirmed by the observed pronounced peaks of symmetrical oscillations of $\mathrm{I}_{3}{ }^{-}$at $115-116 \mathrm{~cm}^{-1}$ in Raman scattering spectra. An additional structural feature is that each terminal iodine atom is connected with three neighboring planar formamidinium cations by $\mathrm{N}-$ $\mathrm{H}$. . I hydrogen bonding with the $\mathrm{N}-\mathrm{H}$. . I bond length varying from 2.81 to $3.08 \AA$, forming a deformed two-dimensional framework of hydrogen bonds. A Mulliken population analysis showed that the calculated charges of hydrogen atoms correlate well with hydrogen-bond lengths. The crystal studied was refined as a three-component twin with domain ratios of 0.631 (1):0.211 (1): $0.158(1)$.

\section{Chemical context}

Polyiodides are a large class of compounds with organic and inorganic cations and a great diversity of anion shapes varying from simple linear $\mathrm{I}_{3}{ }^{-}$up to $\mathrm{I}_{29}{ }^{3-}$ complexes (Svensson \& Kloo, 2003). Such a great diversity of cations and anions allows one to tune the chemical and physical properties of the target compounds. Consequently, polyiodides have attracted great interest for a wide set of applications, such as dye-sensitized solar cells (DSSC) (O`Regan \& Grätzel, 1991; Jeon et al., 2011), different electrochemical devices (Weinstein et al., 2008; Weng et al., 2017) and light-polarizing materials (Kahr et al., 2009).

Another recently proposed prospective application of polyiodides is to use liquid methylammonium and formamidinium polyiodides as a precursor for the fabrication of lightabsorbing materials for perovskite solar cells (Petrov, Belich et al., 2017). Whereas the application of formamidinium polyiodides was shown to be successful for scalable fabrication of solar cells with efficiencies over 17\% (Turkevych et al., 2019), the structures of formamidinium polyiodides have not been studied so far.

In this work, we investigated the features of the new structure of the single-crystalline $\mathrm{CH}_{5} \mathrm{~N}_{2}{ }^{+} \cdot \mathrm{I}_{3}{ }^{-}\left(\mathrm{I}, \mathrm{FAI}_{3}\right)$ phase by means of Raman scattering spectroscopy and DFT calculations. 


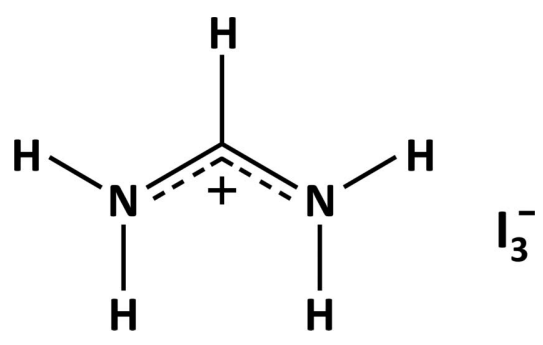

\section{Structural commentary}

Dark-red transparent rhombic-shaped single crystals (Fig. 1a) were obtained by slow heating of preliminary powdered stoichiometric FAI $/ \mathrm{I}_{2}\left(\mathrm{FA}=\mathrm{CH}_{5} \mathrm{~N}_{2}^{+}\right)$mixture up to 355$358 \mathrm{~K}$. Such a temperature range allowed us to obtain wellshaped single crystals as a result of recrystallization from the liquid state near its melting point, which was determined to be $T_{m}=360 \mathrm{~K}$ by visual thermal analysis.

$\mathrm{FAI}_{3}$ was found to crystallize in a triclinic unit cell, space group $P \overline{1}$. The structure (Fig. $1 b$ ) consists of two types of
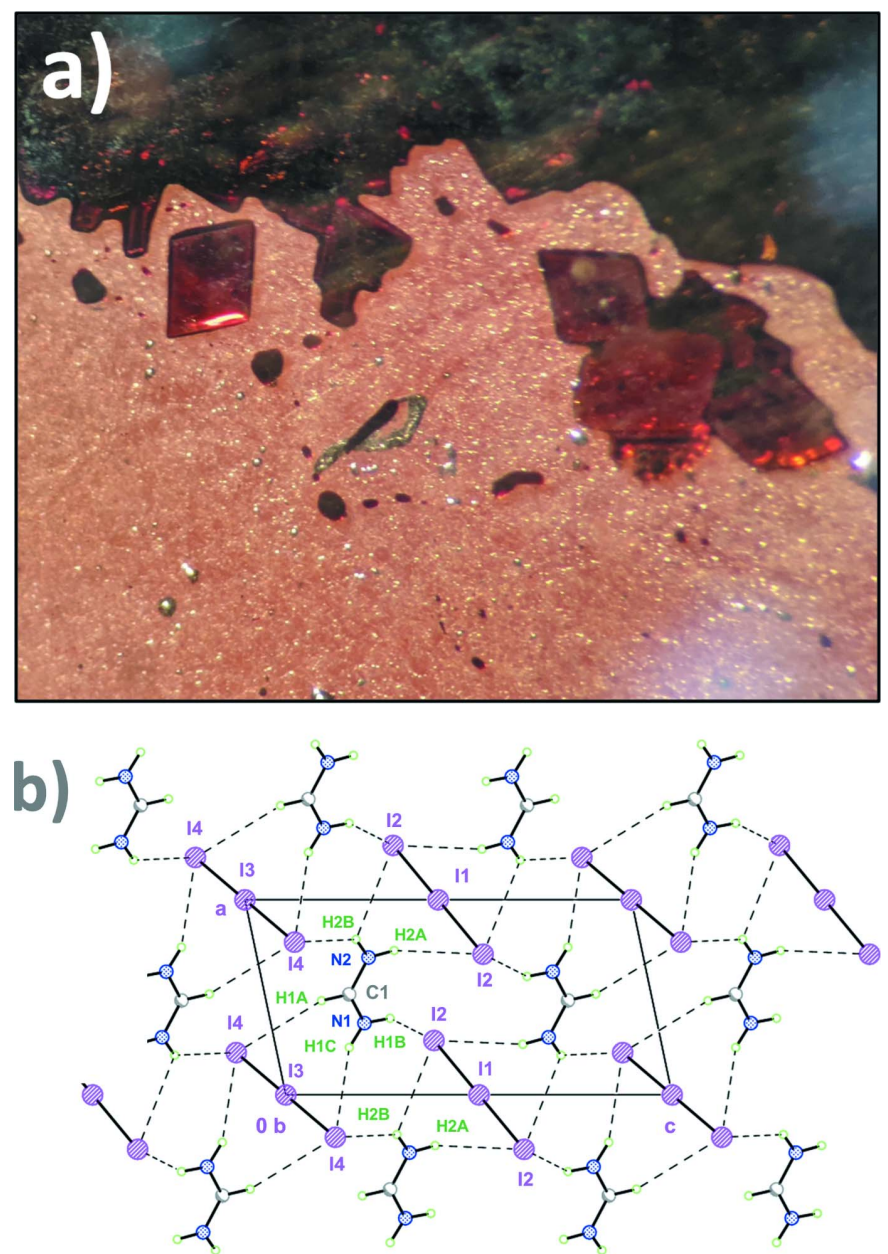

Figure 1

(a) $\mathrm{FAI}_{3}$ single crystals used for the determination of the crystal structure. (b) $\mathrm{FAI}_{3}$ crystal structure with solid lines indicating covalent bonding and dashed lines indicating the intermolecular hydrogen bonds.
Table 1

Hydrogen-bond geometry $\left(\AA,^{\circ}\right)$ and calculated charges for the specified hydrogen atom derived according to the Mulliken scheme.

\begin{tabular}{llllll}
\hline$D-\mathrm{H} \cdots A$ & $D-\mathrm{H}$ & $\mathrm{H} \cdots A$ & $D \cdots A$ & $D-\mathrm{H} \cdots A$ & $\mathrm{H}$ charge \\
\hline $\mathrm{C} 1-\mathrm{H} 1 A \cdots \mathrm{I} 4^{\mathrm{i}}$ & 0.95 & 3.03 & $3.80(2)$ & 138 & 0.152 \\
$\mathrm{~N} 1-\mathrm{H} 1 B \cdots \mathrm{I} 2^{\mathrm{ii}}$ & 0.88 & 3.01 & $3.73(2)$ & 140 & 0.164 \\
$\mathrm{~N} 1-\mathrm{H} 1 C \cdots \mathrm{I} 4^{\mathrm{iii}}$ & 0.88 & 2.92 & $3.74(2)$ & 155 & 0.160 \\
$\mathrm{~N} 2-\mathrm{H} 2 A \cdots \mathrm{I} 2$ & 0.88 & 2.81 & $3.65(2)$ & 161 & 0.171 \\
$\mathrm{~N} 2-\mathrm{H} 2 B \cdots \mathrm{I} 2^{\text {iv }}$ & 0.88 & 3.08 & $3.609(19)$ & 121 & 0.189 \\
$\mathrm{~N} 2-\mathrm{H} 2 B \cdots \mathrm{I} 4^{\mathrm{v}}$ & 0.88 & 2.94 & $3.66(2)$ & 140 & 0.189 \\
\hline
\end{tabular}

Symmetry codes: (i) $-x+1,-y+1,-z+1$; (ii) $-x+1,-y,-z+1$; (iii) $x-1, y-1, z-1$; (iv) $-x, y, z-1$; (v) $-x+2,-y+1,-z+1$.

isolated centrosymmetric triiodide ions ( $D_{\infty h}$ point symmetry) located on centers of inversion. Therefore, only centrosymmetric $\mathrm{I}_{3}{ }^{-}$anions are present, which is rare for structures with relatively small cations such as formamidinium (Svensson \& Kloo, 2003; Gabes \& Gerding, 1972). For instance, in the $\mathrm{CsI}_{3}$ crystal structure, the $\mathrm{I}_{3}{ }^{-}$anion is asymmetric $\left(C_{s}\right.$ point symmetry) with $\angle(\mathrm{I}-\mathrm{I}-\mathrm{I})=178^{\circ}$ (Runsink et al., 1972). For a similar $\mathrm{CH}_{3} \mathrm{NH}_{3} \mathrm{I} / \mathrm{I}_{2}$ system, the $\mathrm{CH}_{3} \mathrm{NH}_{3} \mathrm{I}_{3}$ structure was not isolated (Petrov et al., 2019).

The centrosymmetric character of the $\mathrm{I}_{3}{ }^{-}$anions in $\mathrm{FAI}_{3}$ was confirmed by Raman scattering spectroscopy. The Raman spectrum recorded using a $633 \mathrm{~nm}$ laser (Fig. 2) contains a pronounced peak of $v_{1}\left(\mathrm{I}_{3}{ }^{-}\right)$symmetrical oscillations at $116 \mathrm{~cm}^{-1}$ with an additional $235 \mathrm{~cm}^{-1} 2 v_{1}\left(\mathrm{I}_{3}{ }^{-}\right)$peak and an asymmetrical $v_{3}\left(\mathrm{I}_{3}{ }^{-}\right)$component at $126 \mathrm{~cm}^{-1}$ (Svensson \& Kloo, 2003). The latter might be observed because of the presence of two types of $\mathrm{I}_{3}{ }^{-}$units in the structure with different environments. In addition, no splitting of symmetric oscillations is observed in the Raman spectrum because of the very small difference between the two types of $\mathrm{I}_{3}{ }^{-}$in the structure.

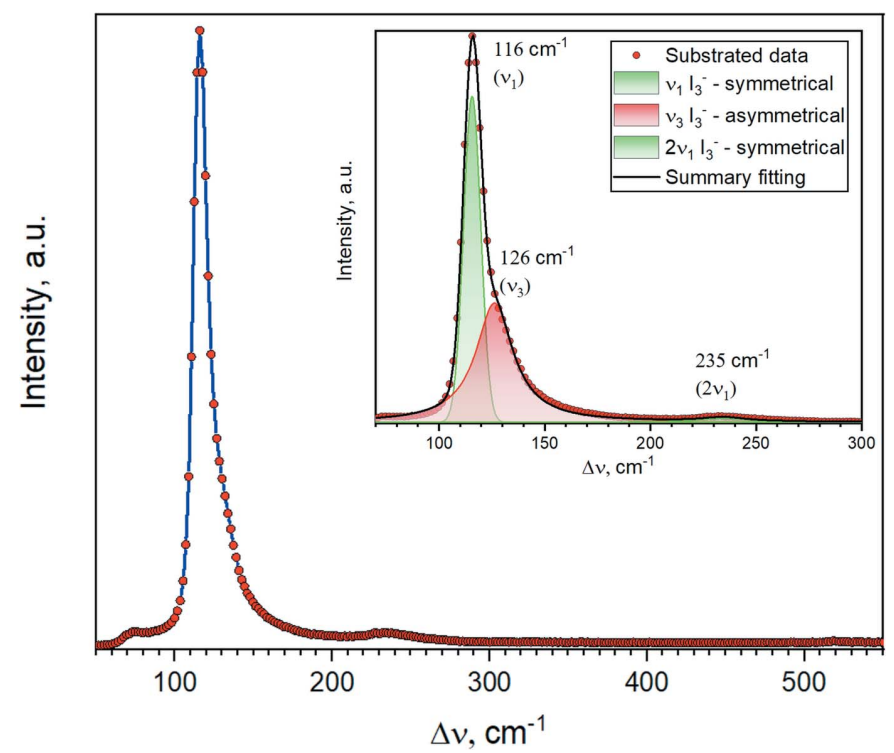

Figure 2

Raman spectrum of a transparent single crystalline plate of $\mathrm{FAI}_{3}$. Laser wavelength, $633 \mathrm{~nm}$; laser power, $20 \mathrm{~mW}$; accumulation time, $1 \mathrm{~min}$. The insert demonstrates the results of spectroscopic analysis. 
Table 2

Calculated Bader atomic charges for the isolated symmetric formamidinium cation. The order of the atoms in the isolated cation matches with that in the formamidinium cation in the refined crystal structure.

\begin{tabular}{llll}
\hline $\mathrm{C} 1$ & +1.31 & $\mathrm{H} 1 C$ & +0.50 \\
$\mathrm{H} 1 A$ & +0.18 & $\mathrm{~N} 2$ & -1.23 \\
$\mathrm{~N} 1$ & -1.23 & $\mathrm{H} 2 A$ & +0.48 \\
$\mathrm{H} 1 B$ & +0.48 & $\mathrm{H} 2 B$ & +0.50 \\
\hline
\end{tabular}

The first of the two types of $\mathrm{I}_{3}{ }^{-}$anions in $\mathrm{FAI}_{3}[d(\mathrm{I} 1-\mathrm{I} 2)=$ $2.9165(14) \AA]$ is connected with three neighboring planar formamidinium cations by $\mathrm{N}-\mathrm{H} \cdots \mathrm{I}$ hydrogen bonding with the bond length varying from 2.81 to $3.08 \AA$ (Table 1 ), which is similar to the distances in formamidinium iodide (Petrov, Goodilin et al., 2017) as well as in other polyiodides (Petrov et al., 2019; Said et al., 2006; van Megen \& Reiss, 2013). The second type of $\mathrm{I}_{3}{ }^{-}$anions are connected by two $\mathrm{N}-\mathrm{H} \cdots \mathrm{I}$ hydrogen bonds of slightly reduced length and a relatively less strong $\mathrm{C}-\mathrm{H} \cdots \mathrm{I}$ hydrogen bond $[d(\mathrm{CH} 1 A \cdots \mathrm{I} 4)=3.03 \AA]$. Such a difference, however, does not change significantly the distance between the central and terminal iodine atoms [2.9165 (14) vs 2.9209 (14) ̊]].

A Mulliken population analysis showed that charges of hydrogen atoms forming a single hydrogen bond with a terminal iodine atom is +0.152 for atom $\mathrm{H} 1 A$, which is
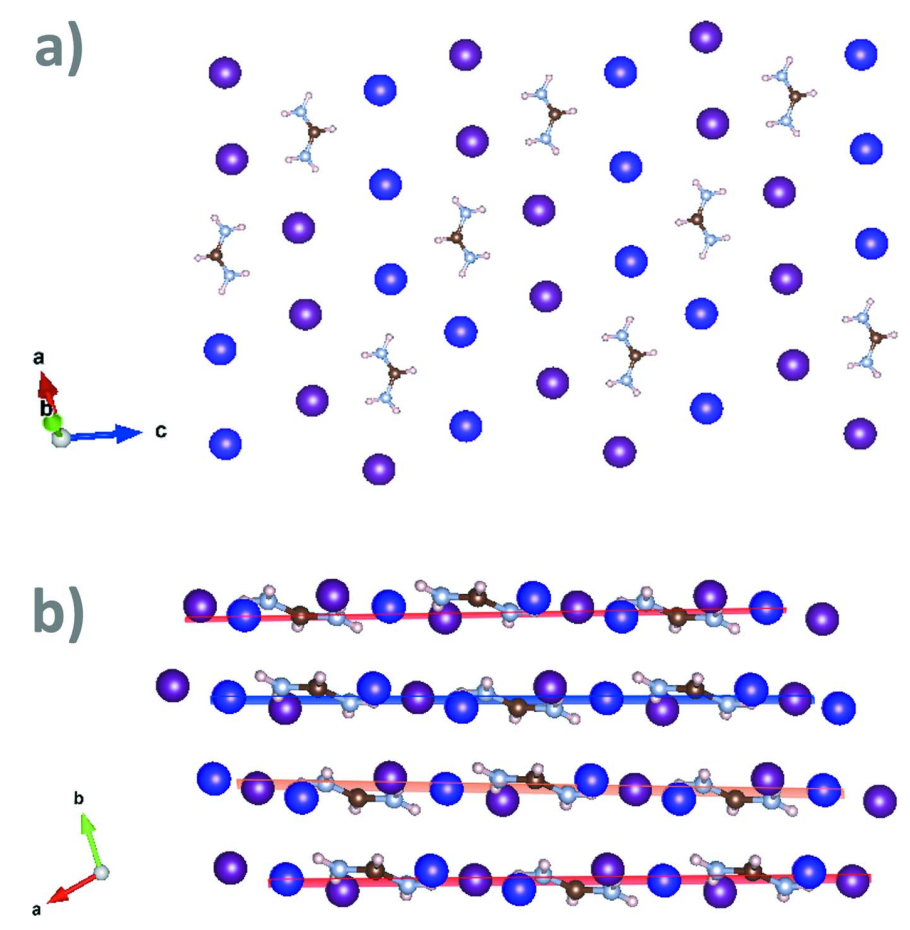

Figure 3

Representation of $\mathrm{FAI}_{3}$ as a deformed cubic close-packed crystal structure with both iodine and formamidinium units in the close-packing layer. Purple and violet atoms represent positions of iodine from the first and second types of $\mathrm{I}_{3}{ }^{-}$, respectively. Formamidinium cations are decreased in size for clarity. (a) A single close-packed layer and (b) representation of $\mathrm{FAI}_{3}$ as a deformed three-layered close-packed structure (the different types of alternating close-packed layers are shown in red, orange and blue).
Table 3

Experimental details.

\begin{tabular}{|c|c|}
\hline \multicolumn{2}{|l|}{ Crystal data } \\
\hline Chemical formula & $\mathrm{CH}_{5} \mathrm{~N}_{2}^{+} \cdot \mathrm{I}_{3}^{-}$ \\
\hline$M_{\mathrm{r}}$ & 425.77 \\
\hline Crystal system, space group & Triclinic, $P \overline{1}$ \\
\hline Temperature $(\mathrm{K})$ & 110 \\
\hline$a, b, c(\AA)$ & $6.0767(10), 6.1886(11), 11.727$ (2) \\
\hline$\alpha, \beta, \gamma\left({ }^{\circ}\right)$ & $97.512(6), 100.345(6), 99.437$ (6) \\
\hline$V\left(\AA^{3}\right)$ & $422.10(13)$ \\
\hline$Z$ & 2 \\
\hline Radiation type & Мо $K \alpha$ \\
\hline$\mu\left(\mathrm{mm}^{-1}\right)$ & 11.01 \\
\hline Crystal size $(\mathrm{mm})$ & $0.26 \times 0.19 \times 0.08$ \\
\hline \multicolumn{2}{|l|}{ Data collection } \\
\hline Diffractometer & $\begin{array}{l}\text { Bruker D8 Quest with Photon III } \\
\text { detector }\end{array}$ \\
\hline Absorption correction & $\begin{array}{l}\text { Multi-scan (TWINABS; Bruker, } \\
\text { 2019) }\end{array}$ \\
\hline$T_{\min }, T_{\max }$ & $0.044,0.092$ \\
\hline $\begin{array}{l}\text { No. of measured, independent and } \\
\text { observed }[I>2 \sigma(I)] \text { reflections }\end{array}$ & $4015,4015,2217$ \\
\hline$(\sin \theta / \lambda)_{\max }\left(\AA^{-1}\right)$ & 0.682 \\
\hline \multicolumn{2}{|l|}{ Refinement } \\
\hline$R\left[F^{2}>2 \sigma\left(F^{2}\right)\right], w R\left(F^{2}\right), S$ & $0.084,0.200,0.98$ \\
\hline No. of reflections & 4015 \\
\hline No. of parameters & 60 \\
\hline No. of restraints & 6 \\
\hline $\mathrm{H}$-atom treatment & $\mathrm{H}$-atom parameters constrained \\
\hline$\Delta \rho_{\max }, \Delta \rho_{\min }\left(\mathrm{e} \AA^{-3}\right)$ & $2.45,-2.52$ \\
\hline
\end{tabular}

Computer programs: APEX3 and SAINT (Bruker, 2019), SHELXT (Sheldrick, 2015a), SHELXL2018 (Sheldrick, 2015b) and SHELXTL (Sheldrick, 2008).

connected with carbon, whereas it is +0.171 for atom $\mathrm{H} 2 \mathrm{~A}$ connected with nitrogen (Table 1), which correlates with the corresponding hydrogen-bond lengths $[d(\mathrm{CH} 1 A \cdots \mathrm{I} 4)=$ $3.03 \AA$ vs $d(\mathrm{NH} 2 A \cdot \cdot \mathrm{I} 2)=2.81 \AA]$. For the $\mathrm{H} 2 B$ hydrogen atom, the high atomic charge $(+0.189)$ is distributed by two hydrogen bonds. An analysis of the Bader atomic charges for the isolated cation also shows a higher charge for the $\mathrm{H} 2 \mathrm{~A}$ atom in comparison with $\mathrm{H} 1 A$ (Table 2), which correlates well with the hydrogen-bond lengths.

Besides, the $\mathrm{FAI}_{3}$ structure can be represented as a pseudocubic close-packed structure with both iodine and formamidinium units in the close-packing layers (Fig. 3). In the discussed crystal structure, each center of mass of the formamidinium cation and each iodine have 12 neighbors in the first coordination sphere, resulting in a distorted cuboctahedra occupancy, which is typical for pseudocubic close-packing. In comparison, the formamidinium iodide structure can be described as a pseudohexagonal close-packed structure with both iodine and formamidinium units in the close-packing layers (Petrov, Goodilin et al., 2017).

\section{Synthesis and crystallization}

FAI and $\mathrm{I}_{2}$ were purchased from Dyesol (99.9\% purity) and Ruskhim ( $99 \%$ purity) without further purification. To obtain single crystalline I, the stoichiometric $\mathrm{FAI} / \mathrm{I}_{2}$ mixture was previously powdered in dry air glovebox. After that, the powdered mixture was slowly heated up to $355-358 \mathrm{~K}$ and the 
Table 4

Atomic charges calculated using Mulliken population analysis.

\begin{tabular}{llll}
\hline $\mathrm{C} 1$ & +0.003 & $\mathrm{I} 2$ & -0.388 \\
$\mathrm{H} 1 A$ & +0.152 & $\mathrm{~N} 2$ & -0.049 \\
$\mathrm{~N} 1$ & +0.019 & $\mathrm{H} 2 A$ & +0.171 \\
$\mathrm{H} 1 B$ & +0.164 & $\mathrm{H} 2 B$ & +0.189 \\
$\mathrm{H} 1 C$ & +0.160 & $\mathrm{I} 3$ & -0.044 \\
$\mathrm{I} 1$ & -0.030 & $\mathrm{I} 4$ & -0.383 \\
\hline
\end{tabular}

obtained single crystals were used for the refinement of crystal structure.

\section{Refinement}

Crystal data, data collection and structure refinement details are summarized in Table 3. All $\mathrm{H}$ atoms were found in an electron density-difference map and refined with isotropic displacement parameters. The crystal studied was refined as a three-component twin with domain ratios of 0.631 (1):0.211 (1):0.158(1). The second and third major domains are rotated from the first one by $\sim 180^{\circ}$ about reciprocal axes [101] and [110], respectively.

\section{DFT calculations}

The electronic structure of the crystal $\mathrm{FAI}_{3}$ was calculated using the DMol3 module from the Materials Studio software package (Delley, 2000, 1990). In the applied DFT method, the PBE functional was used with the DNP 4.4 (double numerical plus polarization) basis set of atomic functions with all electron relativistic core treatment. The charges (Table 4) were derived according to Mulliken's scheme. The calculations were performed without further optimization.

Computations of Bader atomic charges were performed in the GAUSSIAN 09 program (Frisch et al., 2016) using density functional theory (PBE0) (Perdew et al., 1996) and the def-2TZVP basis set. The geometry was optimized using the very tight optimization criteria and empirical dispersion corrections on the total energy (Grimme et al., 2010) with Becke-Johnson damping (D3) (Grimme et al., 2011).

Topological analysis of the $\rho(\mathbf{r})$ function, calculations of the $\mathrm{v}\left(\mathbf{r}_{\mathbf{b c p}}\right)$ and integration over interatomic zero-flux surfaces were performed using the AIMAll program (Keith, 2013).

\section{Acknowledgements}

The authors are grateful to Ekaterina Marchenko for her advice and help with the crystal-structure analysis and to Alexey Grishko for the Raman spectroscopy measurements. DFT calculations performed using the Materials Studio software package were carried out using computational resources provided by the Resource Center 'Computer Center of SPbU'. KL acknowledges partial support from the Moscow State University Program of Development. AP and EG thank colleagues from the Joint Research Center for Physical Methods of Research of IGIC RAS for their valuable assistance in the sample analysis.

\section{Funding information}

Funding for this research was provided by the Russian Science Foundation (grant No. 18-73-10224).

\section{References}

Bruker (2019). APEX3, SAINT and TWINABS. Bruker AXS Inc. Madison, Wisconsin, USA.

Delley, B. (1990). J. Chem. Phys. 92, 508-517.

Delley, B. (2000). J. Chem. Phys. 113, 7756-7764.

Frisch, M. J., Trucks, G. W., Schlegel, H. B., Scuseria, G. E., Robb, M. A., Cheeseman, J. R., Scalmani, G., Barone, V., Petersson, G. A., Nakatsuji, H., Li, X., Caricato, M., Marenich, A., Bloino, J., Janesko, B. G., Gomperts, R., Mennucci, B., Hratchian, H. P., Ort, J. V. \& Fox, D. J. (2016). GAUSSIAN 09. Gaussian Inc., Wallingford, CT, USA.

Gabes, W. \& Gerding, H. (1972). J. Mol. Struct. 14, 267-279.

Grimme, S., Antony, J., Ehrlich, S. \& Krieg, H. (2010). J. Chem. Phys. 132, 154104.

Grimme, S., Ehrlich, S. \& Goerigk, L. (2011). J. Comput. Chem. 32, 1456-1465.

Jeon, S., Jo, Y., Kim, K.-J., Jun, Y. \& Han, C.-H. (2011). ACS Appl. Mater. Interfaces. 3, 512-516.

Kahr, B., Freudenthal, J., Phillips, S. \& Kaminsky, W. (2009). Science, 324, 1407-1407.

Keith, T.A. (2013). AIMAll. TK Gristmill Software: Overland Park, KS, USA. http://aim.tkgristmill.com

Megen, M. van \& Reiss, G. (2013). Inorganics, 1, 3-13.

O'Regan, B. \& Grätzel, M. (1991). Nature, 353, 737-740.

Perdew, J. P., Burke, K. \& Ernzerhof, M. (1996). Phys. Rev. Lett. 77, 3865-3868.

Petrov, A. A., Belich, N. A., Grishko, A. Y., Stepanov, N. M., Dorofeev, S. G., Maksimov, E. G., Shevelkov, A. V., Zakeeruddin, S. M., Graetzel, M., Tarasov, A. B. \& Goodilin, E. A. (2017). Mater. Horiz. 4, 625-632.

Petrov, A. A., Fateev, S. A., Zubavichus, Y. V., Dorovatovskii, P. V., Khrustalev, V. N., Zvereva, I. A., Petrov, A. V., Goodilin, E. A. \& Tarasov, A. B. (2019). J. Phys. Chem. Lett. 10, 5776-5780.

Petrov, A. A., Goodilin, E. A., Tarasov, A. B., Lazarenko, V. A., Dorovatovskii, P. V. \& Khrustalev, V. N. (2017). Acta Cryst. E73, 569-572.

Runsink, J., Swen-Walstra, S. \& Migchelsen, T. (1972). Acta Cryst. B28, 1331-1335.

Said, F. F., Bazinet, P., Ong, T.-G., Yap, G. P. A. \& Richeson, D. S. (2006). Cryst. Growth Des. 6, 258-266.

Sheldrick, G. M. (2008). Acta Cryst. A64, 112-122.

Sheldrick, G. M. (2015a). Acta Cryst. A71, 3-8.

Sheldrick, G. M. (2015b). Acta Cryst. C71, 3-8.

Svensson, P. H. \& Kloo, L. (2003). Chem. Rev. 103, 1649-1684.

Turkevych, I., Kazaoui, S., Belich, N. A., Grishko, A. Y., Fateev, S. A., Petrov, A. A., Urano, T., Aramaki, S., Kosar, S., Kondo, M., Goodilin, E. A., Graetzel, M. \& Tarasov, A. B. (2019). Nature Nanotech, 14, 57-63.

Weinstein, L., Yourey, W., Gural, J. \& Amatucci, G. G. (2008). J. Electrochem. Soc. 155, A590-A598.

Weng, G.-M., Li, Z., Cong, G., Zhou, Y. \& Lu, Y.-C. (2017). Energy Environ. Sci. 10, 735-741. 


\section{supporting information}

Acta Cryst. (2021). E77, 692-695 [https://doi.org/10.1107/S2056989021005673]

Crystal structure of new formamidinium triiodide jointly refined by singlecrystal XRD, Raman scattering spectroscopy and DFT assessment of hydrogenbond network features

Artem A. Ordinartsev, Andrey A. Petrov, Konstantin A. Lyssenko, Andrey V. Petrov, Eugene A. Goodilin and Alexey B. Tarasov

Computing details

Data collection: APEX3 (Bruker, 2019); cell refinement: SAINT (Bruker, 2019); data reduction: SAINT (Bruker, 2019); program(s) used to solve structure: SHELXT (Sheldrick, 2015a); program(s) used to refine structure: SHELXL2018 (Sheldrick, 2015b); molecular graphics: SHELXTL (Sheldrick, 2008); software used to prepare material for publication: SHELXTL (Sheldrick, 2008).

Formamidinium triiodide

Crystal data

$\mathrm{CH}_{5} \mathrm{~N}_{2}{ }^{+} \cdot \mathrm{I}_{3}^{-}$

$M_{r}=425.77$

Triclinic, $P \overline{1}$

$a=6.0767$ (10) $\AA$

$b=6.1886(11) \AA$

$c=11.727(2) \AA$

$\alpha=97.512(6)^{\circ}$

$\beta=100.345(6)^{\circ}$

$\gamma=99.437(6)^{\circ}$

$V=422.10(13) \AA^{3}$

Data collection

Bruker D8 Quest with Photon III detector diffractometer

Radiation source: micro-focus sealed X-ray tube Detector resolution: 7.31 pixels $\mathrm{mm}^{-1}$

$\varphi$ and $\omega$ shutterless scans

Absorption correction: multi-scan (TWINABS; Bruker, 2019)

$T_{\min }=0.044, T_{\max }=0.092$

Refinement

Refinement on $F^{2}$

Least-squares matrix: full

$R\left[F^{2}>2 \sigma\left(F^{2}\right)\right]=0.084$

$w R\left(F^{2}\right)=0.200$

$S=0.98$
$Z=2$

$F(000)=368$

$D_{\mathrm{x}}=3.350 \mathrm{Mg} \mathrm{m}^{-3}$

Mo $K \alpha$ radiation, $\lambda=0.71073 \AA$

Cell parameters from 899 reflections

$\theta=3.5-29.1^{\circ}$

$\mu=11.01 \mathrm{~mm}^{-1}$

$T=110 \mathrm{~K}$

Block, red

$0.26 \times 0.19 \times 0.08 \mathrm{~mm}$

4015 measured reflections

4015 independent reflections

2217 reflections with $I>2 \sigma(I)$

$\theta_{\max }=29.0^{\circ}, \theta_{\min }=1.8^{\circ}$

$h=-8 \rightarrow 8$

$k=-8 \rightarrow 8$

$l=0 \rightarrow 15$

4015 reflections

60 parameters

6 restraints

Primary atom site location: structure-invariant direct methods 
Hydrogen site location: inferred from neighbouring sites

H-atom parameters constrained

$$
\begin{aligned}
& w=1 /\left[\sigma^{2}\left(F_{\mathrm{o}}^{2}\right)+(0.0803 P)^{2}+4.4757 P\right] \\
& \text { where } P=\left(F_{\mathrm{o}}^{2}+2 F_{\mathrm{c}}{ }^{2}\right) / 3 \\
& (\Delta / \sigma)_{\max }<0.001 \\
& \Delta \rho_{\max }=2.45 \mathrm{e} \AA^{-3} \\
& \Delta \rho_{\min }=-2.52 \mathrm{e} \AA^{-3}
\end{aligned}
$$

Special details

Geometry. All esds (except the esd in the dihedral angle between two 1.s. planes) are estimated using the full covariance matrix. The cell esds are taken into account individually in the estimation of esds in distances, angles and torsion angles; correlations between esds in cell parameters are only used when they are defined by crystal symmetry. An approximate (isotropic) treatment of cell esds is used for estimating esds involving l.s. planes.

Refinement. Refined as a three-component twin

Fractional atomic coordinates and isotropic or equivalent isotropic displacement parameters $\left(\AA^{2}\right)$

\begin{tabular}{lllll}
\hline & $x$ & $y$ & $z$ & $U_{\text {iso }}^{*} / U_{\text {eq }}$ \\
\hline I1 & 1.000000 & 0.000000 & 0.500000 & $0.0261(5)$ \\
C1 & $0.515(3)$ & $0.307(3)$ & $0.216(2)$ & $0.023(4)$ \\
H1A & 0.481532 & 0.352625 & 0.141658 & $0.027^{*}$ \\
N1 & $0.372(4)$ & $0.157(3)$ & $0.238(2)$ & $0.051(7)$ \\
H1B & 0.396378 & 0.110694 & 0.306643 & $0.061^{*}$ \\
H1C & 0.246338 & 0.097725 & 0.185971 & $0.061^{*}$ \\
I2 & $0.7214(3)$ & $0.2999(2)$ & $0.58692(14)$ & $0.0318(5)$ \\
N2 & $0.705(3)$ & $0.406(4)$ & $0.2867(17)$ & $0.037(5)$ \\
H2A & 0.741417 & 0.369243 & 0.356493 & $0.044^{*}$ \\
H2B & 0.796631 & 0.510952 & 0.264606 & $0.044^{*}$ \\
I3 & 1.000000 & 0.500000 & 1.000000 & $0.0258(5)$ \\
I4 & $0.7825(3)$ & $0.8407(2)$ & $1.10514(14)$ & $0.0313(4)$ \\
\end{tabular}

Atomic displacement parameters $\left(\AA^{2}\right)$

\begin{tabular}{lllllll}
\hline & $U^{11}$ & $U^{22}$ & $U^{33}$ & $U^{12}$ & $U^{13}$ & $U^{23}$ \\
\hline I1 & $0.0268(11)$ & $0.0239(9)$ & $0.0270(11)$ & $0.0069(8)$ & $0.0049(8)$ & $0.0001(9)$ \\
C1 & $0.020(6)$ & $0.023(6)$ & $0.026(7)$ & $0.009(5)$ & $0.006(5)$ & $-0.002(5)$ \\
N1 & $0.047(14)$ & $0.029(11)$ & $0.070(18)$ & $0.005(10)$ & $0.004(12)$ & $-0.003(12)$ \\
I2 & $0.0324(8)$ & $0.0297(8)$ & $0.0338(10)$ & $0.0113(6)$ & $0.0084(7)$ & $-0.0012(7)$ \\
N2 & $0.036(12)$ & $0.055(13)$ & $0.025(11)$ & $0.009(10)$ & $0.015(9)$ & $0.011(10)$ \\
I3 & $0.0297(11)$ & $0.0210(9)$ & $0.0276(11)$ & $0.0071(8)$ & $0.0067(8)$ & $0.0033(8)$ \\
I4 & $0.0377(9)$ & $0.0262(7)$ & $0.0328(9)$ & $0.0128(6)$ & $0.0107(7)$ & $0.0018(7)$ \\
\hline
\end{tabular}

Geometric parameters $\left(A,{ }^{o}\right)$

\begin{tabular}{llll}
\hline $\mathrm{I} 1-\mathrm{I} 2$ & $2.9165(14)$ & $\mathrm{N} 1-\mathrm{H} 1 \mathrm{C}$ & 0.8800 \\
$\mathrm{I} 1-\mathrm{I} 2^{\mathrm{i}}$ & $2.9165(14)$ & $\mathrm{N} 2-\mathrm{H} 2 \mathrm{~A}$ & 0.8800 \\
$\mathrm{C} 1-\mathrm{N} 1$ & $1.25(3)$ & $\mathrm{N} 2-\mathrm{H} 2 \mathrm{~B}$ & 0.8800 \\
$\mathrm{C} 1-\mathrm{N} 2$ & $1.30(3)$ & $\mathrm{I} 3-\mathrm{I} 4$ & $2.9209(14)$ \\
$\mathrm{C} 1-\mathrm{H} 1 \mathrm{~A}$ & 0.9500 & $\mathrm{I} 3-\mathrm{I} 4^{\mathrm{ii}}$ & $2.9209(14)$ \\
$\mathrm{N} 1-\mathrm{H} 1 \mathrm{~B}$ & 0.8800 & & 120.0 \\
$\mathrm{I}-\mathrm{I} 1-\mathrm{I} 2^{\mathrm{i}}$ & 180.0 & $\mathrm{H} 1 \mathrm{~B}-\mathrm{N} 1-\mathrm{H} 1 \mathrm{C}$ &
\end{tabular}




$\begin{array}{llll}\mathrm{N} 1-\mathrm{C} 1-\mathrm{N} 2 & 125(3) & \mathrm{C} 1-\mathrm{N} 2-\mathrm{H} 2 \mathrm{~A} & 120.0 \\ \mathrm{~N} 1-\mathrm{C} 1-\mathrm{H} 1 \mathrm{~A} & 117.3 & \mathrm{C} 1-\mathrm{N} 2-\mathrm{H} 2 \mathrm{~B} & 120.0 \\ \mathrm{~N} 2-\mathrm{C} 1-\mathrm{H} 1 \mathrm{~A} & 117.3 & \mathrm{H} 2 \mathrm{~A}-\mathrm{N} 2-\mathrm{H} 2 \mathrm{~B} & 120.0 \\ \mathrm{C} 1-\mathrm{N} 1-\mathrm{H} 1 \mathrm{~B} & 120.0 & \mathrm{I} 4-\mathrm{I} 3-\mathrm{I} 4^{\mathrm{ii}} & 180.0 \\ \mathrm{C} 1-\mathrm{N} 1-\mathrm{H} 1 \mathrm{C} & 120.0 & & \end{array}$

Symmetry codes: (i) $-x+2,-y,-z+1$; (ii) $-x+2,-y+1,-z+2$. 